\title{
INVESTIGACIÓN
}

Recibido: 25/03/2017---Aceptado: 03/05/2017---Publicado: 15/06/2017

\section{OPINIÓN PÚBLICA E INFOXICACIÓN EN LAS REDES: LOS FUNDAMENTOS DE LA POST-VERDAD}

\section{Public opinion and infoxication in the networks: fundamentals of post-truth}

José Ignacio Niño González1: Universidad Complutense, España. josenino@ccinf.ucm.es

Mario Barquero Cabrero: ESERP, campus de Madrid, España.

mariobarquero@eserp.com

Enrique García García: Periodista, España.

Garcicomunicacion@gmail.com

\section{RESUMEN}

"Post-verdad" es la palabra del año para el 2016 del diccionario Oxford, gracias a las nuevas tecnologías, y a la forma en la que la propaganda política -y la política mismase ha estado sirviendo de ellas. Es una palabra que tiene connotación de falsedad consciente e inconsciente, de manipulación y de revisionismo de la realidad misma. En cierto modo, una evolución de lo que ha sido y es la publicidad y la propaganda históricamente, pero abriendo con su existencia el esencial debate de hasta qué punto la libertad de expresión protege la libertad para faltar a la verdad, y a las intenciones benignas o interesadas que puedan existir detrás de todo ello.

\section{PALABRAS CLAVE}

Post Verdad - redes sociales - Trump -conceptos subjetivos -sobreinformación infoxicación - TIC

\begin{abstract} intentions that may exists behind all of it.

${ }^{1}$ José Ignacio Niño González. Universidad Complutense, España. josenino@ccinf.ucm.es
\end{abstract}

"Post-Truth" is the 2016 year's Word of Oxford dictionary. Thanks to the new communication technologies and the way in which political propaganda - and politics itself - have been making use of them. It's a word with a sense of conscious or unconscious falseness, of manipulation and revisionism of reality. In some way, it is an evolution of what advertising and propaganda have become historically, but creating with its existence the essential debate about to what extent freedom of speech protects the liberty to give false testimony, and in doing so, the good or interested 
Niño Gonzalez, J. A.; Barquero Cabrero, M.; García García, E. Opinión pública e infoxicación en las redes: los fundamentos de la post-verdad

\section{KEY WORDS}

Post-truth - Social networks -Trump - subjective concepts - overinformation infoxication - ICTs

\section{INTELIGÊNCIA EMOCIONAL E EDUCAÇÃO UNIVERSAL: UMA APROXIMAÇÃO}

\section{RESUMO}

Se busca estabelecer a importância e a atenção que se presta atualmente na educação emocional nas instituições superiores: seu valor para a vida e formação dos alunos e para seu êxito pessoal e profissional, assim como o esforço que estiveram fazendo nas instituições educativas para potenciar este conjunto de habilidades. Igualmente nos interessa a percepção das habilidades sociais de estes por parte dos agentes acadêmicos e laborais. Antes de tudo, determinaremos a origem da inteligência emocional como conceito e a evolução da percepção acadêmica de inteligência.

\section{PALAVRAS CHAVE}

Inteligência emocional - Universidade - Modelos de comunicação - gestão de emoções - MEIS

\section{Cómo citar el artículo}

Niño Gonzalez, J. A.; Barquero Cabrero, M.; García García, E. (2017). Opinión pública e infoxicación en las redes: los fundamentos de la post-verdad [Public opinion and infoxication in the networks: fundamentals of post-truth] Vivat Academia, revista de Comunicación, 139, 83-94 doi: 10.15178/va.2017.139.83-94 Recuperado de http://www.vivatacademia.net/index.php/vivat/article/view/1083

\section{1.- INTRODUCCIÓN}

La política de la post-verdad es una cultura política en la que el discurso que se ofrece al público se estructura fundamentalmente a base de apelar a las emociones, sin referencias a los detalles concretos de las políticas (Jeffery, 2016), y mediante la repetición de eslóganes o consignas que ignoran las refutaciones de hechos por parte de la oposición (Davis, 2010). Aunque se ha descrito como un problema contemporáneo, es posible que su tiempo de vida sea mayor, pero se haya visto potenciado por la propagación de las TIC.

El término fue empleado por primera vez por el escritor serbio-americano Steve Tesich que, en el diario “The Nation” alegaba en 1992 (Kreitner, 2016) que tras los últimos grandes escándalos políticos de la nación norteamericana (refiriéndose, por este orden, al Watergate, la condena de Oliver North y la cobertura de la Guerra del Golfo) se 
Niño Gonzalez, J. A.; Barquero Cabrero, M.; García García, E. (2017). Opinión pública e infoxicación en las redes: los fundamentos de la post-verdad

demostraba que "Nosotros, como pueblo libre, hemos decidido libremente que queremos vivir en algún tipo de mundo Post-verdad" (Flood, 2016).

\section{2.- OBJETIVOS}

Nuestra hipótesis se basa en determinar la relación entre los fenómenos previos o intermedios de la infoxicación y la comunicación en Redes sociales, y la polémica realidad actual de la Post-verdad.

Los conceptos éticos y deontológicos sobre el nuevo modo de comunicación electrónica, en la que la verdad y los hechos parecen haber perdido toda su importancia se muestra en comunicaciones tanto provenientes del mundo político como del mundo académico ya que este último ha tratado de explicar aquél.

Lo teóricos de la post-verdad nos servirán de guía para entender este fenómeno, cada vez más implantado en el mundo de la comunicación ya que nuestro objetivo es mostrar los pilares sobre los que se sustentan este tipo de discursos.

\section{3.- METODOLOGÍA}

El proceso inductivo-deductivo nos servirá como herramienta de análisispara este tipo de mensaje que nos llega como receptores. La metodología heurística o de análisis de fuentes, se complementará con los estudios de casos concretos que centran la comunicación en Redes y en la política actual. La realidad dual de la post-verdad es analizada como contenido (analítica textual) dentro del ámbito ético-deontológico como fenómeno socio-comunicativo y como vehículo de mensajes de cualquier signo e intencionalidad.

Los fundamentos que justifican esta investigación se basan en la trascendencia y novedad del tema, ya que se aprecia un interés por el fenómeno de la post-verdad como objeto de estudio académico y como necesidad de comprensión de los cambiantes mecanismos de un mundo tendente a la toma de decisiones.

Se trata de una temática relacionada con la didáctica de los medios de comunicación y la enseñanza en el análisis de los mismos. Se observa necesidad de ampliación de contenidos y herramientas en este ámbito de estudio en relación a investigaciones basadas en el análisis de los nuevos mensajes políticos a nivel internacional.

\section{4.- DISCUSIÓN}

No es un descubrimiento el que los medios tengan sesgos ideológicos: selección de noticias e imágenes, redacción de titulares, edición de declaraciones y profesionalidad selectiva en lo relativo a entrevistas.En Internet, la Pos-verdad viene siendo una realidad en una escala variable: a pequeña escala en foros y webs de interrelación, para ganar pequeños debates sobre toda una variedad de temas. El llamado fenómeno "Troll" de Internet es un ejemplo, y ya aquí está presente el conflicto entre la mentira evidente e interesada, y la comprobación de hechos. En el ámbito de la red, un troll es un usuario que se dedica a publicar mensajes ofensivos o intencionadamente falsos, apuntando a dañar a una comunidad virtual o simplemente a distorsionar la realidad. 
El concepto se aplica igualmente a los perfiles en línea falsos que se crean con el fin de difundir información errónea bajo el manto del anonimato.

Comúnmente asociados a los foros de internet, se pueden dar en enciclopedias en línea, blogs, grupos de noticias, secciones de comentarios e incluso en juegos online de todo tipo. Se suele pensar que estos usuarios actúan movidos por la búsqueda de atención, si bien un estudio más detenido llevado a cabo por Griffiths (2014) sugiere que, desde un punto de vista psicológico, se trata de personas con perfiles sádicos, psicópatas y maquiavélicos: "una manifestación del sadismo más cotidiano" (Buckels, Trapnell \& Paulhus, 2014).

Separados de la vertiente psicológica, un partido político o grupo de interés, puede perfectamente crear artificialmente trolls (en su acepción de perfiles falsos) para publicar información adulterada o falsa sobre un rival, en un intento de que, con poca inversión de recursos Internet magnifique el mensaje falaz en su beneficio.

El fenómeno tiene, desde luego, notables parecidos: tanto en el caso de los políticos adeptos de la postverdad, como en el del "Trol" digital, la presentación consistente de pruebas y hechos refutadores no parece surtir el efecto que debería. Más bien al contrario, provoca una reacción comparable a la de arrojar agua a una sartén caliente: el trol/postverdadista re-incide en su mentira, ampliándola en el mejor de los casos, o combinándola con un ataque ad hominem contra quien ha presentado la documentación comprometedora. La diferencia más importante es que el trol empieza y termina su comunicación en soledad: con poco o ningún apoyo dentro de la comunidad a la que ataca. El practicante de Postverdad juega con un esquema más peligroso: mezcla la manipulación de los hechos y la explotación de la relatividad nietzschiana con la tendencia natural de la audiencia a secundar ciegamente los mensajes que son afines a sus creencias. El éxito de la política de la postverdad es fruto en muy buena medida, de la negativa colectiva y social a guiarse en función de los hechos antes que en función de las emociones: la generalización de este tipo de contenido noticiable hace, más que nunca, que en el actual proceso creativo sea decisiva la formación del receptor, no sólo por una forma determinada de estructurar y ordenar la realidad, sino también, y especialmente, por los criterios de selección de las fuentes atendiendo a su veracidad (Caldevilla, 2013): una mejora cualitativa de la forma en que el ciudadano participa en la comunicación, ahora que cuantitativamente tiene la capacidad de actuar y reaccionar sobre ella a un nivel global. De acuerdo con Mut Camacho:

[...] en el siglo XXI la opinión pública ha cristalizado en un ente supranacional con vida propia. La opinión pública se ha materializado en un movimiento social a escala planetaria, donde jamás la humanidad y su opinión tuvieron tanta presencia. Miles, millones de personas en todos los países, en los últimos años, salen a la calle a manifestarse contra la guerra, contra los gobiernos, contra medidas legislativas, contra la economía, etc. Estas acciones son la concretizaron de la opinión pública latente. Una concretización que va permaneciendo de forma continuada, mostrando al mundo que existen unánimes actitudes frente a un tema social o político o económico. Por otra parte, gracias a las nuevas tecnologías, ahora la opinión pública es capaz de organizarse mejor y más rápidamente, además de anunciarse, y toda esta situación significa el advenimiento de la población mundial al poder político de 
Niño Gonzalez, J. A.; Barquero Cabrero, M.; García García, E. (2017). Opinión pública e infoxicación en las redes: los fundamentos de la post-verdad

sus países (y de los demás países), y anuncia una reducción de los poderes estatales mediante la incidencia directa en los asuntos públicos de la libre discusión de los particulares a escala mundial. (Mut Camacho, 2012, pp. 3 y 4)

Joyanes (2000) habla directamente de la era de la Post-información, y de la necesidad de una preparación no solamente tecnológica, sino también cultural para afrontar las consecuencias de la mudanza colectiva a la aldea global de McLuhan.

Ampliando el concepto, Caldevilla habla de inteligencia colectiva y de cómo ésta se ha visto potenciado por esta nueva realidad:

La verdadera revolución histórica que supone las TT.II.CC. para el posterior desarrollo colectivo de la humanidad radica en las aportaciones colectivas, en los esfuerzos comunes $\mathrm{y}$, en definitiva, en la unificación de avances en una dirección predeterminada. "La inteligencia colectiva es una forma de inteligencia que surge de la colaboración y concurso de muchos individuos". Tal definición surge de los trabajos de Peter Russell (1983), Tom Atlee (1993), Pierre Lévy (1997), Howard Bloom (1995), Francis Heylighen (1995), Douglas Engelbart, Cliff Joslyn, Ron Dembo\& Gottfried Mayer-Kress (2003) (Caldevilla, 2008, p. 139)

Pero como toda inteligencia, la inteligencia colectiva es susceptible a las emociones, y precisa de información para sacar sus propias conclusiones. Si la información que se le suministra está adulterada, o si la inteligencia colectiva se encuentra "infoxicada" con datos contradictorios $\mathrm{y} / \mathrm{o}$ sobreabundantes, no es razonable esperar que tome decisiones acordes a su interés o su trasfondo cultural. Un ejemplo reciente de postverdad e infoxicación de la realidad lo tenemos en la polémica surgida en torno al número de asistentes a la toma de posesión de Donald Trump como presidente de los Estados Unidos:

Sean Spicer, nuevo jefe de prensa de la Casa Blanca, aseguró al ser preguntado por la cifra de asistentes a la inauguración del presidente Trump que esta había convocado "al mayor público en cualquier inauguración, punto, tanto en persona como alrededor del mundo". Sin embargo, imágenes de diferentes medios mostraron una audiencia significativamente menor a la de la asunción de Obama, que además contrastó con las multitudinarias manifestaciones en contra del presidente electo en varias ciudades de Estados Unidos. Spicer adujo frente a los periodistas de la Casa Blanca que 420.000 personas tomaron el metro de la ciudad ese día contra 317.000 en la inauguración de Barack Obama, pero las cifras de la red de transportes citadas por The Washington Post, hablan de 570.557 viajes del pasado viernes frente a 1,1 millones con Obama en 2009 y 782.000 en el día de la inauguración de su segundo mandato, en 2013.

La experta en encuestas y opinión pública Kellyane Conway, [...] Cuestionada por las cifras de asistentes, Conway -ahora investida como asesora presidencialrespondió a un periodista que decir que la Casa Blanca había dado datos falsos sobre la asistencia al evento era "exagerado" y que estos datos presentados por Spicer eran "hechos alternativos a eso" (Bryan Smith para AFP, 2017). 
La sociedad tiene acceso a la información, pero carece colectivamente de la voluntad para dedicarse a su comprobación. Al mismo tiempo, desconfía crónica, incremental e incluso justificadamente de los profesionales y medios cuya labor es garantizar la veracidad de la información y destapar el fraude. Errores de bulto, como la magnificación artificial de la mal llamada "pandemia" de la Gripe A han contribuido indudablemente a ello, según indica en sus conclusiones Costa-Sánchez (2011):

Los titulares empleados en los textos sobre la nueva gripe no se pueden considerar mayoritariamente de tipo divulgativo. En primer lugar, hay un amplio porcentaje de titulares apelativos $(32,7 \%)$, que tienen como misión principal la de atraer la atención de los lectores. En segundo lugar y aunque la presencia de titulares de tipo informativo es mayoritaria, su finalidad se aleja de la divulgación puesto que se corresponden con textos que anuncian la expansión del virus y sus consecuencias en términos de muertes y afectados. A nivel cualitativo, se refuerza la tesis de un estilo de redacción sensacional, en el que el virus o la gripe se convierten en un protagonista que viaja a través del mundo afectando a distintos países y causando numerosas víctimas. Esto da lugar a lo que recogen las cabeceras como una especie de guerra del mundo contra la gripe A, en la que debemos armarnos para luchar contra su propagación. La prensa, por tanto, no deja de explotar lo sensacional [...] en los grupos de titulación. (Costa-Sánchez, 2011, p. 40)

Una realidad que nos lleva directamente a la preparación cultural de la que hablaba Joyanes (2000). La propia Conway fue poco después protagonista de otro caso en el que podríamos hablar bien de manipulación consciente de la información, o bien de simple y llana falta de atención a la hora no ya de comprobarla sino de leerla en su totalidad: en una entrevista ante la MSNBC justificó los decretos de veto migratorio que el presidente Trump intentaba imponer contra diversos países musulmanes, amparándose en que "Obama impuso un veto de seis meses al programa de refugiados iraquíes después que dos iraquíes vinieran al país, se radicalizaran y fueran ideólogos de la masacre de Bowling Green",añadiendo a continuación que dicha masacre "nunca fue cubierta por la prensa" (AFP, 2017, p. 1).

La historia documentada, sin embargo, cuenta que esos dos ciudadanos iraquíes fueron en efecto detenidos, bajo los cargos de intentar enviar armas y dinero a Irak, y por haber empleado IED (Improvised Explosive Devices o Artefactos explosivos Improvisados) contra fuerzas estadounidenses antes de salir del país árabe. Pero no por ninguna masacre acaecida en la ciudad donde fueron detenidos (Bowling Green, Kentucky) A raíz de ello Obama no suspendió el programa de refugiados iraquíes, como afirmaba Conway, sino que simplemente endureció los controles de antecedentes que ya se llevaban a cabo.

Estamos hablando de una de las principales estrategas informativas que han facilitado el triunfo de Trump, y a la que la prensa ya ha apodado "Ministra de propaganda". White (2017) resume la situación que en la que se encuentra la comunicación pública global del siguiente modo: La libre circulación de mentiras maliciosas, la inefectividad de la comprobación de hechos, la resistencia demostrada por la propaganda populista, racismo y sexismo y la emergencia de la así llamada post-verdad parece desafiar una piedra angular del periodismo ético -el que los hechos importan para la democracia y 
que la gente quiere estar bien informada cuando se la llama a hacer decisiones de calado. También desafía, en lo tocante a las nuevas tecnologías, las ideas de Villar (2004) suscritas por Fombona y Pascual-Sevillano (2011) respecto a que "Internet representa una escala hacia la alta autonomía y la certificación del pluriculturalismo de la diferencia".

Como señala Sánchez Leyva:

El nuevo capitalismo demanda y crea redes de interdependencia para las que ordena que ejerzamos nuestras habilidades emocionales para identificarnos con el punto de vista de otros anulando el conflicto social, nos pide que nos construyamos una personalidad a la medida de los requerimientos socioeconómicos en una relectura del interés propio en términos de coaching adaptativo como salud emocional. Fraguando vínculos solidarios entre solitarios de los que quede al margen la justicia.

Se ha instaurado el reino del "yo mismo" que conlleva, entre otros aspectos, que pensemos que nuestras emociones tienen validez por el simple hecho de que las expresamos, que nuestras opiniones (que consideramos propias) tienen validez porque son "nuestras" y proceden no ya de un saber sino de una experiencia "propia" (poder y querer frente a saber y hacer). Y que la expresivización es fruto de la espontaneidad. Se impone así una horizontalidad falsificada sin autoridad ni criterio reconocido que equipara y nos separa. El "narcisismo" complaciente contemporáneo que es ¿paradójicamente? un narcisismo de masas, producido y promocionado por dispositivos de masas (moleculares, en términos Deleuzianos) se acompaña pues de una expresivización que en realidad imposibilita el diálogo o la confrontación social: enquistados en un lenguaje sentimental ya consignado, además de "en lo que sentimos", damos vía libre a una "sinceridad" que sólo delata una sospecha de su interlocutor. La "espontaneidad" que este proceso requiere aboca a la dramatización como género discursivo. (Sánchez Leyva, 2015, p.254)

Lo que nos lleva al componente emocional del fenómeno de la post-verdad: anunciantes comerciales y políticos basan sus propuestas en la presentación de símbolos y valores comunes y universales, en vez de en contenidos y propuestas, que son siempre discutibles. No solo en lo relativo al significado enteramente subjetivo que puede darse a conceptos como "Dios" "Libertad" "Patria" o "Prosperidad" sino en lo tocante a ejemplos de la otra orilla ideológica, como el mal entendido concepto de la globalización (Díez Medrano).En su estudio "Consumo de medios de comunicación y actitudes hacia la prensa por parte de los universitarios" Parrat Fernández (2010) sostiene que Sólo un 4\% (de los encuestados por ella) recurre a él (el periódico) como complemento de otros medios, al contrario de la idea extendida de que la función de este medio será cada vez más la de ampliar la información ofrecida de antemano por los demás. A este respecto quizás cabría pensar que, incluso en el caso de los universitarios interesados por estar al día de las últimas noticias, dicho interés no es suficiente para llevarles a informarse por varios medios diferentes. De hecho, casi son tantos los que ven el periódico como instrumento lúdico y didáctico (44\% entre ambos) como quienes lo conciben como medio informativo (47\%). 
Niño Gonzalez, J. A.; Barquero Cabrero, M.; García García, E. Opinión pública e infoxicación en las redes: los fundamentos de la post-verdad

Finalmente, queremos recordar, a modo de colofón, un desiderándum que ya expresara Caldevilla en 2010: "Hay que reconocer la necesidad de la ética en la configuración de la sociedad y de la propia empresa, y proponerse fomentar su estudio y puesta en práctica" (Caldevilla, 2010, p. 109)

\section{5.- CONCLUSIONES}

Los públicos se han convertido en participantes activos del proceso comunicativo. A efectos prácticos, cada persona es potencialmente la editora y redactora de su propia información, gracias a las facilidades que para ello crean las nuevas tecnologías y los filtros de contenido personalizados.

Sin embargo, esta libertad no se traduce en un tratamiento más preciso de la información, sino en un acercamiento más estrecho de esta a la forma de pensar de cada receptor. Bloqueando en destino toda influencia que la información crítica con determinados puntos de vista pueda tener en el público final. En otros casos, las exigencias de la vida digital y de la inmediatez que conlleva hacen que no resulte una actitud natural por parte de estos nuevos públicos-actores el comprobar las informaciones: requiere demasiado tiempo, demasiado esfuerzo y demasiada atención continuada, en unos tiempos en los que escasea hasta el tiempo para la hora de comer. El hecho de que, además, el público general pueda producir su propio contenido informativo con los mismos déficits de objetividad con que lo consume, lleva a la generalización de la infoxicación: tanto en su vertiente de exceso de información, como en la de informaciones total o severamente, voluntaria o involuntariamente adulteradas. El público es editor de su propia información, y de su propia desinformación: se convierte en herramienta de su propia manipulación por parte de grupos de interés al dar eco a noticias e informaciones determinadas, de manera incluso más eficiente y con menos margen de error de lo que supondría el enviarla a los medios tradicionales.

Dichas informaciones, distribuidas a través de las redes sociales y aplicaciones de dispositivos inteligentes (Por ejemplo: Whatsapp) con técnicas de SEO(destaque en buscadores) y clickbait (cíber-anzuelo), son amplificadas y voceadas por personas afines al contenido, que no se molestan en comprobar unos datos que, desde su punto de vista, son creíbles. Posteriormente estos contenidos provocan comentarios y distribución adicional por parte de usuarios de signo contrario que expresan su desacuerdo. También por parte de medios tradicionales en busca de las audiencias digitales y de información sensacional. Incluso su denuncia como bulos o informaciones tóxicas se convierte en difusión positiva, porque en definitiva se ha llegado a esos públicos que combinan falta de fe en los medios y la inclinación a creer la noticia adulterada en primera instancia. Incluso si eso significa llegar también a quienes, por razones diversas -ideológicas, éticas, pragmáticas, personales- rechazan el mensaje.

Los medios digitales facilitan además llegar a públicos especializados con mensajes personalizados: el "Micro-targeting" (híper segmentación de consumidores). Lo que facilita que segmentos de la población que no comulgan con un mensaje determinado, puedan igualmente adherirse a él por interés, atendiendo a las partes del mismo que les incumben directamente y que podrían beneficiarles. La forma en que las 
necesidades económicas han moldeado y siguen moldeando la mentalidad individual y colectiva lleva, aparentemente, a una circunstancia en la que la empatía hacia el prójimo -entendido como el desconocido- comienza a ser menos y menos relevante en la decisión del voto y en la asunción de mensajes sociales. De acuerdo con Leyva, nuestros puntos de vista son válidos porque son nuestros, y la sinceridad ha quedado reducida a la expresión desnuda, hiriente incluso, de sensaciones y percepciones.

Estamos, pues, ante un escenario preocupante en el mejor de los casos: aquel en el que el público es manipulado a través del propio público, y de medios estrictamente anónimos: los usuarios. En sus manos está, cada vez más, la selección final de información, pero todo parece indicar que seguimos lejos del momento cultural en el que el público sea capaz de ejercer esta función de forma crítica. Una realidad solo empeorada por la dificultad intrínseca de procesar la creciente cantidad de información contradictoria que recibimos, y la también ardua e ingrata tarea de enfrentar los prejuicios individuales. El escenario de actuación necesaria para los próximos años se ha ampliado desde el ámbito de la comunicación al de la educación ciudadana. Es posible que en el futuro cercano tengamos que plantearnos un imposible dilema entre la clase de hombre social que requieren los mercados, y el que requiere la sociedad libre.

\section{6.- REFERENCIAS}

Agencia France Presse (3/02/2017). La creadora de los "datos alternativos" de Trump ahora inventó un ataque iraquí. El Observador. Recuperado de: www.elobservador.com.uy/la-creadora-los-datos-alternativos-trump-ahorainvento-un-ataque-iraqui-n1025725

Bryan Smith (para Agencia France Presse) (23/01/2017). Spicer, Conway y los "datos alternativos", El Observador. Recuperado de: www.elobservador.com.uy/spicerconway-y-los-datos-alternativos-n1022754

Buckels, E. E.; Trapnell, P. D. \& Paulhus, D. L (2014). Trolls just want to have fun, Personality and Individual Differences, 67, 97-102.doi: https://doi.org/10.1016/j.paid.2014.01.016

Caldevilla Domínguez, D. (2008). El nuevo modelo de comunicación a partir de las redes sociales y las TT.II.CC, Revista de comunicación de la SEECI, 16, 115145.doi: $\underline{\text { http://dx.doi.org/10.15198/seeci.2008.16.115-145 }}$

Caldevilla Domínguez, D. (2010). La cara interna de la comunicación en la empresa. Madrid: Visión Libros.

Caldevilla Domínguez, D. (2013). Efectos actuales de la "Sobre información" y la "Infoxicación" a través de la experiencia de las bitácoras y del proyecto I+D avanza 'Radiofriends', Revista de comunicación de la SEECI, 30, 34-56.doi: http://dx.doi.org/10.15198/seeci.2013.30.34-56 
Niño Gonzalez, J. A.; Barquero Cabrero, M.; García García, E. Opinión pública e infoxicación en las redes: los fundamentos de la post-verdad

Costa-Sánchez, C. (2011). Tratamiento informativo de una crisis de Salud pública: los titulares sobre la gripe A en la Prensa Española, Revista de Comunicación de la SEECI, 25, 29-42. doi: http://dx.doi.org/10.15198/seeci.2011.25.29-42

Davis, R.(2010). Post-truth politics. Recuperado de: http://grist.org/article/2010-03-30-post-truth-politics/

Díez Medrano, J. (2010). Gestión de la comunicación en la sociedad del siglo XXI: Un 'arma' sutil para una globalización bajo sospecha, Revista de Comunicación de la SEECI, 22, 1-15.doi: https://doi.org/10.15198/seeci.2010.22.1-15

Davis, R. (2010). Post-truth politics. Recuperado de: http://grist.org/article/2010-03-30-post-truth-politics/

Flood, A. (15/11/2016). Post-truth' named word of the year by Oxford Dictionaries. The Guardian. Recuperado de: www.theguardian.com/books/2016/nov/15/post-truth-named-word-of-theyear-by-oxford-dictionaries

Fombona Cadavieco, J. \& Pascual Sevillano, M. Á. (2011). Las tecnologías de la información y la comunicación en la docencia universitaria. Estudio de casos en la Universidad Nacional Autónoma de México (UNAM), Educación XXI, 14, 79110. Recuperado de http://www.redalyc.org/articulo.oa?id=70618742004

Griffiths, M. D. (2014). Adolescent trolling in online environments: A brief overview, Education \& Health, 32(3), 85-87. Recuperado de http://sheu.org.uk/x/eh323mg.pdf

Jeffery, T. (26/06/2016). Britain Needs More Democracy After the EU Referendum, Not Less. The Huffington Post. Recuperado de: www.huffingtonpost.co.uk/tomjeffery/britain-needs-more-democr_b_10699898.html

Joyanes Aguilar, L. (2000).Cambio tecnológico y nueva sociedad de la información (cibersociedad), en Vivat Academia, Revista de Comunicación, 16, 1-12.doi: https://doi.org/10.15178/va.2000.15.1-12

Kreitner, R. (30/11/2016).Post-Truth and Its Consequences: What a 25-Year-Old Essay Tells Us About the Current Moment. The Nation. Recuperado de www.thenation.com/article/post-truth-and-its-consequences-what-a-25-yearold-essay-tells-us-about-the-current-moment/

Mut Camacho, M. (2012). Apuntes sobre la opinión pública a pie de calle, Revista de Comunicación de la SEECI, 28, 1-10. doi: https://doi.org/10.15198/seeci.2012.28.1-10 
Niño Gonzalez, J. A.; Barquero Cabrero, M.; García García, E. (2017). Opinión pública e infoxicación en las redes: los fundamentos de la post-verdad

Parrat Fernández, S. (2010).Consumo de medios de comunicación y actitudes hacia la prensa por parte de los universitarios, Zer, revista de estudios de comunicación, 15(28), 133-149. Recuperado de www.ehu.eus/zer/hemeroteca/pdfs/zer28-08parratt.pdf

Sánchez Leyva, M. J. (2015). Del "yo es otro" al "yo soy yo mismo": emociones y dominación social, Methaodos, revista de ciencias sociales, 3(2), 253-261. doi: http:/ / dx.doi.org/10.17502/m.rcs.v3i2.89

Villar Angulo, L. M. (2004). Cuestiones tecnológicas de difusa frontera, en F. Martínez, \& M. P. Prendes, Nuevas tecnologías y Educación. Madrid: Pearson.

White, A. (2017). Ethical Journalism Network: Ethics in the News, EJN Report on Challenges for Journalism in the Post-Truth Era, en A. White, (Coord.) Fake News: Facebook and Matters of Fact in the Post-Truth Era (pp. 14-17). Londres: Ethical Journalism Network. Recuperado de: http:/ / ethicaljournalismnetwork.org/wp-content/uploads/2017/01/ejnethics-in-the-news.pdf

\section{AUTORES}

\section{José Ignacio Niño González}

Profesor Asociado en el departamento de Comunicación Audiovisual y Publicidad II de la Facultad de Ciencias de la Información, Universidad Complutense de Madrid, impartiendo la asignatura "Investigación y Planificación de Medios". Magíster en Gestión Publicitaria impartiendo la asignatura "El advergaming como nuevo medio publicitario" en la Facultad de Ciencias de la Información de la Universidad Complutense de Madrid. Desde 2010, dirige "Global Digital Marketing". Sus principales trabajos de investigación son los proyectos de Innovación y Mejora de la Calidad Docente: "El aula virtual como escenario de mediación para la interculturalidad y los derechos humanos" en la Universidad Complutense de Madrid. http:// orcid.org/0000-0003-2775-7241

\section{Mario Barquero Cabrero:}

Fue profesor titular de la Universidad Rey Juan Carlos de Madrid y, desde hace más de veinte años es Director General de ESERP Business School: Escuela Superior de Ciencias Empresariales, Marketing y Relaciones Públicas en Madrid. Consultor en comunicación y relaciones públicas, es autor de varios trabajos en disciplinas tan interconectadas como el marketing, la empresa, finanzas, las relaciones públicas y la comunicación.

https://scholar.google.es/citations?user=6TgLW4YAAAAJ\&hl=es

\section{Enrique García García:}

Licenciado en Periodismo, Humanidades y CC. de la Información por la Universidad San Pablo CEU. Máster CES en Periodismo Audiovisual. Director del Magazine 
Niño Gonzalez, J. A.; Barquero Cabrero, M.; García García, E. Opinión pública e infoxicación en las redes: los fundamentos de la post-verdad

"Cultura Pop", ha cubierto todo tipo de información en su paso por la prensa y la radio: en el diario "el economista", deportes COPE y sociedad para Radio Intercontinental. Ha participado en investigaciones como "Antonio Gramsci y las raíces lejanas del Eurocomunismo: el precedente olvidado" y "Análisis de la comunicación en las instituciones museísticas madrileñas"

http://orcid.org/0000-0002-1872-5013 